\title{
Los trabajos de Persiles y Sigismunda, historia setentrional de Miguel de Cervantes: Estado de la cuestión y su actualidad para hispanistas nórdicos
}

\author{
Randi Lise Davenport (UiT The Artic University of Norway, Norway)
}

\begin{abstract}
Miguel de Cervantes' posthumous novel, Los trabajos de Persiles y Sigismunda, historia setentrional, published in 1617, has in the past decades received renewed attention from Cervantes scholars. This article gives an overview of the main perspectives of current research at the $400^{\text {th }}$ anniversary of the novel that the author himself considered his literary testament. It concludes offering some brief reflections on its particular relevance for Nordic hispanists.
\end{abstract}

Keywords: Cervantes, Los trabajos de Persiles y Sigismunda, state of the art, literary criticism, Siglo de Oro

\section{Introducción}

La última novela de Miguel de Cervantes, publicada póstumamente en Madrid en 1617, goza actualmente de un renovado interés entre los críticos, como se ve en las varias efemérides celebradas en distintos lugares por los 400 años de su publicación. Este renovado interés crítico por esta última obra, que el propio Cervantes consideró su mejor logro y testamento literario, complementa y amplía considerablemente los primeros estudios "modernos" de Joaquín Casalduero (1947) y de Alban K. Forcione (1970 y 1972). Investigaciones que fueron continuadas con otras perspectivas, entre ellas una visión feminista sobre la obra, como los estudios de Ruth El Saffar (1984) y Diana de Armas Wilson (1991). Desde la década de 1990 una pluralidad de nuevas interpretaciones han enriquecido al "gran Persiles", que fue considerada por muchos críticos, hasta esta época, como una obra "anticuada" y malograda en comparación con la "modernidad" de Don Quijote (1605 y 1615). Partiendo de los mencionados importantes estudios de Forcione, entre otros, esta interpretación ha sido definitivamente superada en las últimas décadas por los estudios monográficos de Isabel Lozano-Renieblas (1998, 2014), Michael Nerlich (2005), William Childers (2006) y de Michael Armstrong-Roche (2009), por mencionar algunas de las más modernas aportaciones sobre la obra.

Este artículo reseña brevemente la recepción y "recuperación" del Persiles dentro de los estudios cervantinos, incluyendo un panorama de las conferencias impartidas y de los volúmenes monográficos de revistas editados en los últimos años de conmemoraciones cervantinas, con una particular mención al Congreso Internacional Cervantes en el 
Septentrión celebrado en la Universidad Ártica de Noruega, en Troms $\varnothing$, a finales de junio de 2017 con la participación de 80 cervantistas de unos 18 países. ${ }^{1}$

Primero presentaremos la novela, antes de enfocar su recepción y las actividades críticas recientes, incluyendo un panorama temático de las contribuciones académicas ofrecidas en el congreso mencionado. Dados los aspectos "septentrionales" de esta obra y la atención particular que se prestó a estos temas en el congreso de Tromsø, el artículo se centrará en ellos, y concluirá con unas reflexiones acerca de la relevancia de Los trabajos de Persiles y Sigismunda, historia setentrional para profesores y estudiosos de español en las universidades nórdicas.

\section{2. ¿Qué es el Persiles?}

Para realizar un breve resumen (o no tan corto) de Los trabajos de Persiles y Sigismunda, historia setentrional, es inevitable "destripar" de la trama. Obviamente, cualquier resumen revela asimismo cierta lectura de la obra: ¿Es el Persiles una novela de ortodoxia cristiana, que sintetiza la vida como peregrinaje en el cual la pareja de protagonistas, de hermosura inconmensurable, abandona el Norte bárbaro y oscuro para ser catequizados y casados en la luz de la capital Contrarreformista, Roma? (Casalduero, Avalle-Arce, Forcione); ¿o es más bien una "comedia divina y humana proto-protestante" en la que Cervantes con la alegoría e ironía se mantiene a salvo de los censores y de la Inquisición? (Nerlich). Estos dos extremos de interpretaciones del siglo $\mathrm{XX}$ son un botón de muestra de la riqueza interpretativa que provoca esta obra de Cervantes.

¿Pero qué es el Persiles? Otra manera de resumir la novela sería indicando su estructura externa, compuesta por un total de 79 capítulos, divididos en cuatro libros: el primer contiene 23; el segundo, 21; el tercero, también 21, mientras que el cuarto y último solamente tiene 14 capítulos. Para muchos críticos la brevedad del último libro y la conclusión algo apresurada de la trama es una señal de la prisa que tenía el autor por terminar su obra antes de morir.

Si nos fijamos, a continuación, en los demás elementos paratextuales habituales en los libros del siglo XVII, destacan la dedicatoria al Conde de Lemos y el prólogo de exquisito y estremecedor humor cervantino:

\footnotetext{
“'Puesto ya el pie en el estribo, / con las ansias de la muerte, / gran señor, ésta te escribo.' Ayer me dieron la extremaunción y hoy escribo ésta; el tiempo es breve, las ansias crecen, las esperanzas menguan y, con todo esto, llevo la vida sobre el deseo que tengo de vivir." (Cervantes 2004, 116-117). ${ }^{2}$
}

La acción de los dos primeros libros de esta "historia septentrional" está situada en el mar y entre islas del extremo norte de Europa, algunas de ellas reconocibles en mapas como la Carta marina (Venecia, 1539), del obispo católico sueco exiliado en Roma, Olau Magno, o en el también famoso Theatrum Orbis Terrarum (Amberes, 1570) de Abraham Ortelio, mientras

\footnotetext{
${ }^{1}$ La página web de la conferencia con su programa y los títulos de las comunicaciones sigue accesible en: [www.uit.no/cervantes2017]

${ }^{2}$ Cervantes cita dos coplas antiguas en su dedicatoria al Conde de Lemos, a quien también había dedicado las Novelas ejemplares (1613), Ocho comedias (1615), y la Segunda parte del Quijote (1615). Es fechada el 19 de abril de 1616, tres días antes de su muerte. Contando con que en 1614 también salió su poema seriocómico Viaje del Parnaso, en el que "reseña" a los poetas de su tiempo, se puede apreciar cómo una gran parte de la producción literaria de Cervantes se concentra en sus últimos años de vida.
} 
que los libros tres y cuarto tienen lugar en tierra firme - conocida por los lectores contemporáneos- desde la que los protagonistas y su séquito ponen pie en Lisboa, atraviesan España, el sur de Francia y el norte de Italia hasta llegar a Roma, donde termina la novela. Aunque también en el último libro los personajes nos dan información sobre el norte, sobre Noruega, en particular en el capítulo 12, en el cual se nos confirma que el destino final de los protagonistas no es Roma, sino su lugar de origen, adonde vuelven a vivir felices: "y vivió [Sigismunda] en compañía de su esposo Persiles hasta que bisnietos le alargaron los días, pues los vio en su larga y feliz posteridad" (Cervantes 2004, 714).

Un elemento decisivo de la obra es la transferencia geográfica y cultural de personajes meridionales al Norte de Europa en los dos primeros libros, y de los dos protagonistas septentrionales y de otros personajes secundarios del Norte al Sur. Entre esos personajes se incluye también la familia "mestiza", plurilingüística- y pluricultural, resultado de estas transferencias, como es el matrimonio mixto entre la bárbara Ricla y el náufrago español Antonio de Villaseñor y sus dos hijos, frutos de esta unión: Antonio el (semi-)bárbaro y su hermana Constanza, que fielmente acompañan hasta Roma a los dos protagonistas "hermanos", Auristela y Periandro, es decir en realidad, Sigismunda, princesa de Frislanda, y Persiles, príncipe segundón de Tule enamoradísimo de la princesa prometida a su hermano mayor Maximino.

Sería despreciar tanto al lector primario como a los posteriores pensar que no sospecha que el desenlace para la pareja protagonista sea celebrar su matrimonio al final de la obra, después de pasar por muchos trabajos: de naufragios, costumbres bárbaras (y meridionales, habrá que añadir), raptos de piratas, magia, enfermedad, separaciones, celos, pretendientes y anhelos religiosos. Después de todo Cervantes había anunciado que con esta obra quería competir con la más prestigiosa novela de amor griega, tal como la traducían y apreciaban los preceptistas renacentistas. Así lo daba a conocer en el prólogo al lector de sus Novelas ejemplares (1613), dedicada, igual que el Persiles, al Conde de Lemos: "libro que se atreve a competir con Heliodoro, si ya por atrevido no sale con las manos en la cabeza" (Cervantes 2010, 52-53). Como es bien sabido, el autor de esas novelas se enorgullecía de haberlas engendrado de su propio ingenio, y parido de su pluma, asegurando que no eran imitadas ni hurtadas. Y no menores expectativas, así pues, crea en el lector ante su última obra. En el Viaje del Parnaso (1614) la menciona de esta forma:

"Yo estoy, cual decir suelen, puesto a pique

para dar a la estampa al gran Persiles,

con que mi nombre y obras multiplique."

(Cervantes 2016, cap. IV, vv 46-48).

Y finalmente, en la dedicatoria al Conde de Lemos del 31 de octubre de 1615 de la segunda parte del Quijote, la caracteriza de esta sabrosa manera:

"con esto me despido, ofreciendo a Vuestra Excelencia Los trabajos de Persiles y Sigismunda, libro a quien daré fin dentro de cuatro meses. Deo volente; el cual ha de ser o el más malo o el mejor que en nuestra lengua se haya compuesto, quiero decir de los de entretenimiento; y digo que me arrepiento de haber dicho el más malo, porque, según la opinión de mis amigos, ha de llegar al extremo de bondad posible" (Cervantes 1998, $623)$.

La referencia a Heliodoro remite a la novela Etiópicas, o Historia de Teágenes y Cariclea, del autor en lengua griega Heliodoro de Emesa (Homs, Siria), escrita en la época 
imperial (siglo IV a. C.), y que fue recuperada y elogiada como modelo para la épica moderna por los humanistas del Renacimiento, entre otros por el doctor y "filósofo de la literatura", Alonso López Pinciano, en su Philosophia antigua poética, de 1596. Comenta el cervantista Edward C. Riley que Cervantes estaba a la "vanguardia literaria" de su tiempo al tomar a Heliodoro como modelo, si bien según este mismo crítico, Cervantes fracasa al querer conseguir lo que logra Heliodoro: muchas historias secundarias, o paralelas, del Persiles desvían al lector de la trama principal (Riley 1992, 53). Recordemos que en el Persiles se nombran a 78 personajes, y entre ellos muchos tienen licencia para contar sus historias. Sin embargo, a diferencia de Riley, Forcione sostiene que las llamadas "digresiones" o "subtramas" complementan o reflejan la trama principal. (Forcione 1972, 142-148). Como veremos, los primeros lectores del Persiles eran del mismo parecer que este crítico, al menos si se tiene en cuenta el éxito editorial de la obra.

\section{Brevísima relación de la recepción, destrucción y recuperación del Persiles, siglos XVII-XX.}

Cervantes acertó con su "atrevimiento", aunque no llegase a saborear el éxito: su última novela se imprimió en siete ciudades el mismo año de su aparición: Madrid, Barcelona, Valencia, Pamplona, Lisboa, París y Bruselas, y se reimprimió regularmente hasta la década de 1630. Se tradujo al francés en 1618, al inglés en 1619 y al italiano en 1626. En el siglo XVIII hubo varias traducciones al alemán (la primera en 1746). También hay una traducción al portugués conservada en manuscrito de esta época.

El Persiles se leyó y se valoró positivamente a lo largo del siglo XVII hasta ser "destronado" por las revaloraciones y reinterpretaciones del Quijote, que pasó por la lectura irónica-satírica inglesa del siglo XVIII y por la idealista del romanticismo alemán del siglo $\mathrm{XIX}^{3}$, hasta ser considerada como la obra que está en el origen de la novela realista moderna, y también como texto principal de la metaficción. Así, el Persiles fue relegado al olvido genérico o visto, incluso, como un "lapsus genérico" por parte de su envejecido autor (o hasta como obra senil e inverosímil, en opinión de Menéndez Pelayo, y de otros). Sin embargo, es más que probable que Cervantes estuviera trabajando en paralelo en sus últimas obras: la tan reconocida metaficción de la segunda parte del Quijote, y su "gran Persiles", que quiso que fuera su testamento literario. Muchos han visto también en la "crítica literaria" que hace el canónigo de Toledo en la Primera parte del Quijote (I, 47) una descripción del proyecto del Persiles, de larga gestación.

Las lecturas alegóricas del Persiles fueron las dominantes durante su recuperación crítica en el siglo XX, pero han cambiado de cuño: desde las críticas que lo vieron "como un alarde de ortodoxia religiosa" a las nuevas lecturas que lo aprecian como "una alegoría de la diferencia que conecta con las preocupaciones de nuestro tiempo". (García Berrio y LozanoRenieblas 2017, 7).

A continuación, presento una breve bibliografía restringida a estudios monográficos dedicados al Persiles en el siglo XX, además de la de las primeras dos décadas del siglo XXI,

\footnotetext{
${ }^{3}$ Huelga precisar que los autores románticos apreciaron la novela como prototipo de la novela romántica, pero en general el Persiles cayó en desestima hasta su lenta recuperación crítica en el siglo XX, con un notable incremento de diversidad de perspectivas y enfoques, amén de cantidad de aportaciones críticas, en las últimas décadas.
} 
si bien, en primer lugar, enumero algunas de las ediciones más importantes, empezando por la prínceps, publicada a inicios del 1617 por la viuda del autor, Catalina de Salazar y Palacios:

- Los trabajos de Persiles y Sigismunda, historia setentrional, Madrid, Juan de la Cuesta, 1617.

- Los trabajos de Persiles y Sigismunda. Obras completas de Miguel de Cervantes Saavedra, III-IV, edición de Rodolfo Schevill y Adolfo Bonilla, Madrid, Imprenta de Bernardo Rodríguez, 1914.

- Los trabajos de Persiles y Sigismunda, edición de Juan Bautista Avalle-Arce, Madrid, Castalia, 1969.

- Los trabajos de Persiles y Sigismunda, edición de Carlos Romero Muñoz, Madrid, Cátedra, 1997, 2ª edición revisada 2002 (con la bibliografía actualizada hasta 2001).

- Los trabajos de Persiles y Sigismunda, edición de Florencio Sevilla Arroyo y Antonio Rey Hazas, Madrid, Alianza Editorial, con la colaboración del Centro de Estudios Cervantinos, 1999.

- Los trabajos de Persiles y Sigismunda, edición de Isaías Lerner y Isabel LozanoRenieblas, Barcelona, Penguin Clásicos, 2016.

- Los trabajos de Persiles y Sigismunda, texto crítico de Laura Fernández, notas de Ignacio García Aguilar, notas complementarias de Carlos Romero Muñoz, estudio de Laura Fernández e Isabel Lozano-Renieblas, Madrid, Biblioteca Clásica de la Real Academia Española, 2017. ${ }^{4}$

Como ya ha quedado dicho, la obra se tradujo a las lenguas europeas más importantes de la época; y aunque en esta ocasión no incluyamos un panorama de las traducciones modernas, huelga comentar que la traducción moderna al inglés de Clark Colahan y Celia Richmond Weller de 1989 (con reimpresiones posteriores), es de buena y amena lectura, e incluye además, en apéndice, algunas de las ilustraciones de la Historia de Gentibus Septentrionalibus (Roma, 1555, Historia de los pueblos del norte) de Olau Magno. Es muy probable que tenga importancia para la relativa 'popularidad' actual del Persiles en los departamentos de español en las universidades norteamericanas. Y como veremos más adelante, los aspectos relativos a la sociología de la literatura también tiene importancia para la posición del Persiles en Francia.

Obviamente, por ser una lista restringida a las monografías, faltarán algunos estudios importantes como los artículos o secciones de libros de estudiosos como Frederick de Armas, Luis Avilés, Agustín Redondo, Steven Hutchinson o Mercedes Blanco, por mencionar unos pocos.

1900-1999

- Cesare de Lollis Cervantes reazionario (1924)

\footnotetext{
${ }^{4} \mathrm{Al}$ revés del caso de la edición prínceps, que estaba lista para imprimir a finales del 1616, pero que lleva el año 1617 en la portada y se imprimió a inicios del nuevo año, esta edición lleva el año 2017 en la portada, pero no salió de la imprenta hasta enero de 2018. Como bien se sabe, el primer Quijote se imprimió a finales de 1604, pero con el año ' 1605 ' en la portada para alargar el periodo de su 'novedad'.
} 
- Joaquín Casalduero Sentido y forma de "Los Trabajos de Persiles y Sigismunda" (1947)

- Alban K. Forcione Cervantes' Christian Romance (1972)

- Ruth El Saffar Beyond Fiction. The Recovery of the Feminine in the Novels of Cervantes (1984)

- Diana de Armas Wilson Allegories of Love. Cervantes' "Persiles y Sigismunda" (1991)

- Amy Williamsen Co(s)mic Chaos: Exploring Los trabajos de Persiles y Sigismunda (1994)

- Aurora Egido Cervantes y las puertas del sueño (1994)

- Julio Baena El círculo y la flecha: Principio y fin, triunfo y fracaso del 'Persiles' (1996)

- Isabel Lozano-Renieblas Cervantes y el mundo de Persiles (1998)

La monografía de Lozano-Renieblas sigue siendo fundamental para un cabal entendimiento de la obra, en particular para comprender el espacio septentrional de la novela, basado en el concepto bajtiniano del 'cronotopo'.

$2000-$

- Maria Alberta Sachetti Cervantes' "Los trabajos de Persiles y Sigismunda". A Study of Genre (2001)

- Jean-Marc Pelorson El desafío del "Persiles" (2003)

- Michael Nerlich El Persiles descodificado, o la "Divina Comedia" de Cervantes (2005)

- William Childers Transnational Cervantes (2006)

- Michael Armstrong-Roche Cervantes' Epic Novel. Empire, Religion and the Dream Life of Heroes in Persiles (2009)

- Mercedes Alcalá Galán Escritura desatada: poéticas de la representación en Cervantes (2009)

- Isabel Lozano-Renieblas Cervantes y los retos del "Persiles" (2014)

Es preciso señalar el caso particular del cervantismo / 'persilismo' francés, por el hecho de que en el año universitario 2003-2004 el Persiles figuraba en el programa de las oposiciones a cátedras (de la llamada "Agrégation" y del "Capes") de español en Francia, lo que explica el título de Pelorson en la lista (es también traductor del Persiles al francés en la colección La Pléiade).

En cuanto a revistas con secciones monográficas dedicadas al Persiles, hay que mencionar como un ejemplo de la importancia del cervantismo norteamericano para la 
recuperación crítica del Persiles, que el Bulletin del Cervantes Society of America Cervantes ya en el 1990 dedicó un número al Persiles (volumen 10.1, de acceso abierto en línea) con artículos de Juan Bautista Avalle-Arce, Diana de Armas Wilson, Ruth El Saffar, Julio Baena, George Mariscal, Amy Williamsen, y Clark Colahan, entre otros. Mencionaré otras publicaciones relacionados con congresos más adelante, pero si nos limitamos a las revistas académicas con secciones monográficas dedicadas al Persiles en los últimos años, cabe mencionar las siguientes:

- Anuario de Estudios Cervantinos, volumen XI, 2015, titulado: El pensamiento literario del último Cervantes del Parnaso al Persiles, editado por Jesús G. Maestro.

- Anales Cervantinos. Los números correspondiendo a 2015 y 2016 cuentan con varios artículos dedicados al Persiles (acceso abierto en línea)

- eHumanista Cervantes, 2016, titulado "Si ya por atrevido no sale con las manos en la cabeza: el legado poético del 'Persiles' cuatrocientos años después”, editado por Mercedes Alcalá Galán (acceso abierto en línea. Comentaré este volumen más abajo).

Y en revistas no especializadas se puede mencionar al número 837 de Ínsula. Revista de Letras y Ciencias Humanas (2016) dedicada a la influencia escandinava en la literatura española: Entre España y Escandinavia: De Cervantes al Nordic Noir, con una contribución de la autora de este artículo en colaboración con Carlos F. Cabanillas Cárdenas sobre Noruega en la literatura del Siglo de Oro, donde hay una sección dedicada al Persiles. (https://www.insula.es/revista/entre-espana-y-escandinavia-de-cervantes-al-nordic-noir). El último número de la Revista de Occidente de 2017 (número 439) también está dedicado a Cervantes y el Persiles. Final de obra y principio de la gloria.

Y en cuanto a los congresos dedicados al Persiles desde el año 2000, donde primero cabe destacar al "Quinto Congreso Internacional de la Asociación de Cervantistas", que se celebró en Lisboa en 2003, con dos plenarias sobre el Persiles (Agustín Redondo y Aurora Egido), más 55 comunicaciones dedicadas a la obra póstuma de Cervantes (accesibles en línea bajo el título Peregrinamente peregrinos, 2004).

$\mathrm{Y}$ en los últimos años conmemorativos cervantinos, cabe mencionar, si bien es lista no exhaustiva, los siguientes:

2015: El XX Congreso de la Asociación Alemana de Hispanistas celebrado en Heidelberg, dedicó una sección, con 15 comunicaciones, al Persiles, publicada con el título Ficciones entre mundos: nuevas lecturas de "Los Trabajos de Persiles y Sigismunda", editado por Jörg Dünne y Hanno Ehrlicher (Edition Reichenberger, 2017).

2016: La Cervantes Society of America organizó una sesión dedicada al Persiles en la 62 a Reunión Anual del Renaissance Society of America, en Boston.

2017: En el aniversario de la publicación del Persiles se celebraron varios congresos y seminarios, y me detendré naturalmente en el celebrado en Troms $\varnothing$ en junio, aunque no sin mencionar primero a estos otros:

- "Cervantes y los mares en los 400 años del Persiles", Universidade Nova de LisboaCentro de Humanidades, 16-18 de noviembre, celebrado 14 años después del VCINDAC en la misma ciudad con un enfoque sobre el Persiles. 
- "XIII Coloquio Internacional de la Asociación de Cervantistas. Los trabajos de Cervantes", Argamasilla de Alba, 23-25 de noviembre.

- "Lecciones cervantinas 2. El Persiles en su IV Centenario (1617-2017)", organizado por el Grupo de Investigación Siglo de Oro (GRISO) en colaboración con el Instituto de Estudios Auriseculares (IDEA) en la Universidad de Navarra, Pamplona, 14-15 de diciembre.

Es una gran satisfacción poder constatar que el congreso celebrado en Troms $\varnothing$ fue uno de los máximos eventos académicos en torno al Persiles en su año conmemorativo; por la gran calidad de las contribuciones, por reunir 80 cervantistas de 18 países, y por estar dedicado exclusivamente a la última novela de Cervantes. ${ }^{5}$ En particular se puede destacar la buena 'mezcolanza' de cervantismo europeo y americano - del sur y del norte- entre las 64 comunicaciones presentadas. En cuanto a la participación nórdica echamos de menos participantes de Dinamarca, pero contábamos con ponentes de Suecia, Finlandia y Noruega. Las plenarias del congreso fueron:

- Frederick de Armas (University of Chicago, presidente de la Asociación Internacional Siglo de Oro/AISO): "The Vanishing Architectures of Persiles, Books I-II" (en inglés por ser plenaria inaugural, la mayoría de las comunicaciones se presentaron en español).

- Isabel Lozano-Renieblas (Dartmouth College, presidenta de la Asociación de Cervantistas/AC): "Alegoría, ideología y anagogía en Los trabajos de Persiles y Sigismunda"

- Michael Armstrong-Roche (Wesleyan University) "La mirada lucianesca y las ironías de la ejemplaridad en el Persiles"

- José Manuel Lucía Megías (Universidad Complutense de Madrid, presidente de honor de la AC): “"Este es el manco sano, el famoso todo, el escritor alegre, y finalmente, el regocijo de las musas': notas para una biografía cervantina sin el 'Persiles"'.

\section{Temas actuales destacados}

La editora del volumen 5 de eHumanista Cervantes, Marcedes Alcalá Galán, también presente en nuestro congreso septentrional, sostiene que "el sentido del Persiles no es ideológico sino estético, pues al fin se nos descubre como una inmensa fábula sobre la narración y su falta de límites, siendo el testamento literario de su autor." (2016, iii). Efectivamente, podemos comprobar que igual que en el volumen monográfico de dicha revista, un poco más de la mitad de las comunicaciones en el congreso septentrional fueron dedicadas a la poética del texto, en sentido amplio. Por ejemplo, en las comunicaciones sobre la utilización de las funciones paradigmáticas de los personajes del cuento según la teoría de Propp (Michel Moner), o sobre el papel del diálogo según el teórico italiano Sigonio del siglo XVI y según Bajtín (José Manuel Martín Morán), hasta variaciones sobre la écfrasis, como la relación de la obra con el arte de su tiempo (de la propia Alcalá Galán). El concepto de

\footnotetext{
${ }^{5}$ Una selección de artículos del congreso se ha publicado en el número 7.1 de Hipogrifo. Revista de literatura y cultura del Siglo de Oro (2019), y las plenarias y otra selección de artículos se han recogido en bajo el título Cervantes en el Septentrión (editado por R.L. Davenport \& I. Lozano-Renieblas) en el número 57 de la colección Batihoja del Instituto de Estudios Auriseculares, en versión impresa y digital, de acceso abierto.
} 
'heterotopía' de Foucault se ha aprovechado en dos comunicaciones, centradas en las islas septentrionales (Marsha Collins), y en la oscilación entre los papeles utópicos o distópicos de Roma y los paisajes septentrionales (Stephen Hessel).

También apuntamos varias comunicaciones sobre el arte de la voz y los sonidos en la obra (Gustavo Illades, Nieves Rodríguez Valle, Juan A. Sánchez), incluso una sesión (la única enteramente en inglés) con el membrete de "Cervantine Soundscapes" - un término moderno inglés para "los sonidos que forman un ambiente sonoro" y que en este caso recoge los elementos peregrinos (también en el sentido de 'extranjero') o de viaje y movimiento en la obra (Natalia Pérez, Sherry Velasco, Sonia Velázquez). Otra 'onda' de comunicaciones, por así decirlo, relacionaron el espacio marítimo (Santiago Fernández Mosquera), o el mar mismo, con los afectos (Paul Johnson) y el alma (Mónica Poza Diéguez), algunas de ellas quizás apuntando hacia el campo relativamente nuevo en humanidades de los llamados 'estudios oceánicos'.

Aunque abogando por el sentido estético del Persiles, Alcalá Galán no quiere desmentir la validez de las interpretaciones éticas de la obra en su introducción al eHumanista Cervantes-en sentido tan amplio como en el caso del sentido de poética.

Cabe decir que en el congreso septentrional tampoco faltó esta perspectiva, en sentido tan diverso como el mencionado por la editora: "la justicia, la verdad, la prudencia, la barbarie, la otredad, la discapacidad, religión, estudios de género, guerra, imperialismo, mundos alternativos, y una revisión del asunto morisco" (2016, iv). En el caso de estudios de género lo encontramos relacionado con el tema de la hechicería y licantropía (Hilaire Kallendorf, Ruth Fine, Adrienne Martin). Tampoco faltaron las comunicaciones que se enfocaron en el episodio del maestro de danzar italiano Rutilio, que termina en Noruega transportado en un manto volante por una hechicera romana, según cuenta, desde el aspecto de la representación y función de la magia meridional y septentrional (Christian Andrès, María Cristina Pascerini, María José Rodilla León).

Como era de esperar, el congreso convocó particularmente temas relacionados con el Septentrión, y contó por lo tanto con comunicaciones sobre el significado del pasado mítico godo en la obra (Adrián Sáez) o la imagen clásica del bárbaro y los pueblos del norte (Antonio Sánchez Jiménez) desde la perspectiva de la imagología, por ejemplo. Otro enfoque sobre la construcción del personaje bárbaro femenino, Ricla, la pone en relación con el conocido relato del naufragio de Pietro Querini en la isla de Røst (Davenport).

A pesar de hacer este resumen temático según una división de las comunicaciones en 'poéticas' y 'éticas' -en sentido muy amplio, por cierto-, tal vez la propuesta más interesante sea romper un poco con esta dicotomía entre la 'poética' y la 'ética' en las interpretaciones de la obra y señalar -tal como lo hace Michael Armstrong-Roche- el aspecto serio ludere, es decir, seriocómico, de la novela, explorando las huellas de otro escritor de lengua griega, Luciano de Samosata (siglo II d. C.). La ironía e inversión de perspectiva presente en los diálogos de Luciano fue muy apreciado por los humanistas italianos, igual que por Erasmo y Tomás Moro. Sus huellas son asimismo notables en un amplio legado de la literatura española del siglo XVI. Según Armstrong-Roche, ésta última novela "de entretenimiento" (en las palabras de Cervantes mismo), aprovecha el juego paradoxográfico de la tradición lucianesca: por ejemplo, en el hecho de que sus protagonistas / héroes septentrionales permiten una mirada 'ingenua' sobre el mundo conocido. Por otra parte, la 'ejemplaridad' de los protagonistas es también ambigua, en sintonía con este aspecto seriocómico. 


\section{Hacia una conclusión: La relevancia del Persiles en el Septentrión}

Con motivo del congreso cervantino en la Universidad Ártica de Noruega, se organizó también una exposición en la Biblioteca Universitaria, ya que la biblioteca cuenta con un ejemplar de la edición prínceps de la Historia de Gentibus Septentrionalibus (Roma 1555) de Olau Magno, una de las principales fuentes de conocimiento del mundo septentrional en la época de Cervantes. La exposición incluyó reproducciones de varias de las ilustraciones de la obra y de otras fuentes cartográficas. Sin embargo, como demostró el presidente del Cervantes Society of America, Steven Hutchinson, en su comunicación en el congreso, Cervantes se sirve de la información que le proporciona el obispo y cartógrafo sueco muy a su manera. Por ejemplo, transfiere parte de la información que ofrece la inmensa Carta marina (Venecia 1539) sobre el interior de Escandinavia hacia las islas en el mar.

El papel de la obra de Olau Magno en la construcción del Persiles no parece ser un campo agotado para la investigación, como nos lo demostraron en el Congreso Septentrional también las comunicaciones de Hutchinson, Colahan, Rodríguez Valle y Sánchez Jiménez, entre otros. A esta sazón hay que mencionar el artículo de María Carmen Díaz de Alda Heikiläa, "Última Thule y el contexto nórdico de Los trabajos de Persiles y Sigismunda", publicado en 2001 en las actas del IV Congreso de la Asociación Internacional de Cervantistas (Illes Baleares, 2000), que aprovecha la colección cartográfica de la Biblioteca Nacional de Finlandia (La colección Nordenskiöld, 1832-1901) para "averiguar si el mundo nórdico representado en la novela se corresponde con el conocimiento que se tenía de los países septentrionales a principios del siglo XVII” (Díez de Alda Heikiläa 2001, 875).

$Y$, aunque falta comentar las comunicaciones sobre influencias, referencias, adaptaciones e intertextualidad, y sobre las traducciones -que también las hubo en el congreso septentrional-,Olau Magno nos tiende un buen puente hacia la conclusión de esta presentación: unas mínimas reflexiones sobre la relevancia de la última novela de Cervantes para los profesores e hispanistas escandinavos. Porque, a pesar de su obvia conexión con el mundo nórdico es una obra muy poco conocida en las universidades escandinavas.

Con este artículo espero haber demostrado la vitalidad y actualidad de los estudios cervantinos dedicados en particular a Los trabajos de Persiles y Sigismunda, historia setentrional. No se puede ocultar que la enseñanza de la literatura y cultura del Siglo de Oro en general tiende a reducirse a un mínimo en los programas de español como lengua extranjera, por lo menos en los niveles del bachelor. No obstante, aun así, el Quijote sigue siendo un referente obligatorio para cualquier estudiante - o estudioso - de las letras españoles. Sin embargo, no sería un despropósito traer a colación la historia septentrional para que los estudiantes escandinavos de español tengan un conocimiento más cabal del máximo ingenio de la literatura española que además les proporcione unas posibilidades riquísimas de comparaciones culturales entre su cultura de origen y la 'cultura meta'.

\section{Bibliografía}

Alcalá Galán, Mercedes, 2016. "Introducción. 'Si ya por atrevido no sale con las manos en la cabeza': el legado poético del «Persiles» cuatrocientos años después”, eHumanista Cervantes 5, pp. i-viii. 
http://www.ehumanista.ucsb.edu/sites/secure.lsit.ucsb.edu.span.d7_eh/files/sitefiles/ce rvantes/volume5/ehumancer5.finalfinal.option2.pdf

de Cervantes Saavedra, Miguel, 1998. Don Quijote de la Mancha, edición de Francisco Rico, Barcelona: Crítica.

- 2004. Los trabajos de Persiles y Sigismunda, edición de Carlos Romero Muñoz, Madrid: Cátedra.

- 2013. Novelas ejemplares, edición de Jorge García López, Barcelona: Círculo de Lectores / Biblioteca Clásica de la Real Academia Española.

- 2016. Viaje del Parnaso y poesías sueltas, edición de José Montero Reguera y Fernando Romo Feito, Barcelona: Círculo de Lectores Espasa Calpe / Biblioteca Clásica de la Real Academia Española.

Díaz de Alda Heikiläa, María Carmen, 2001. “'Ultima Thule’ y el contexto nórdico de Los trabajos de Persiles y Sigismunda, en: Volver a Cervantes. Actas del IV Congreso Internacional de la Asociación de Cervantistas, ed. Antonio Bernat Vistarini, Palma: Universitat de les Illes Balears, pp. 878-885.

Forcione, Alban K., 1972. Cervantes' Christian Romance: A Study of Persiles and Sigismunda, Princeton: Princeton University Press.

García Berrio, Antonio e Isabel Lozano-Renieblas, 2017. "Términos de Cervantes con el Persiles: final de obra y principio de gloria", Revista de Occidente 439, pp. 5-14.

Riley, Edward C., 1992 [1962]. Cervantes' Theory of the Novel, Newark: Juan de la Cuesta. 